\title{
MEDIA DAN PRODUKSI BUDAYA
}

\author{
Amirudin \\ Program Studi Antropologi, Fakultas Ilmu Budaya \\ Universitas Diponegoro \\ Email: amdjtg@yahoo.com
}

\begin{abstract}
This article discusses the theoretical study of media and cultural production to fill the void in the perspective of media study in the anthropology perspective. This study is focused on how anthropology contributes to the development of media study in relation with the cultural formation. Through the study of Mazzarella's thought (2004) on the concept of mediated culture, and Bourdieu's thought (1993, 2005) and Turner's thought (1974) on the concept of domain (field), this article presents a new idea on how both thoughts are applied in the media study.
\end{abstract}

Keywords: Mass Media, Mediated Culture, Cultural Production Domain.

\section{Pendahuluan}

Sejak tahun 1990-an, poses produksi budaya sebenarnya telah ramai menjadi obyek kajian dalam lapangan studi media. Dalam studi media konvensional, praktik-praktik bermedia umumnya dibagi menjadi empat sub lapangan studi, yakni studi produksi, studi konten/teks, studi audiens, dan studi efek media (Lihat misalnya Valdivia 2003; Williams 2003). Pembagian sub lapangan studi itu didasarkan pada pembatasan proses komunikasi massa yang diasumsikan sebagai proses penyampaian pesan (proses produksi), wujud pesan (konten/teks), penerimaan pesan (audiens), dan hubungan atau dampak dari penyebaran pesan pada masyarakat. Pemetaan Denis McQuail (1983) dalam konteks itu tampaknya sangat berpengaruh dalam literatur studi media, sehingga empat sub lapangan studi tersebut kerap menjadi standar dalam meneliti praktik bermedia.

Meskipun demikian, kajian-kajian media yang memang sifatnya multidisipliner tidak semata didominasi perspektif komunikasi massa yang linier. Berbagai kajian menyuguhkan sudut pandang dan penelaahan yang diperkaya oleh berbagai strategi penelitian ilmuilmu sosial, termasuk di antaranya etnografi yang merupakan ciri khas kajian antropologi. Dipengaruhi terutama oleh Stuart Hall (1980), kajian-kajian media melangkah dengan mempertautkan setiap tahap praktik bermedia dengan keseluruhan proses sosial-budaya.

Kajian tentang audiens, misalnya, tidak lagi menempatkan khalayak terisolasi dari aktivitasnya dalam kehidupan sehari-hari. Audiens bukan penerima pesan yang pasif, melainkan juga aktif melakukan pembacaan dan penafsiran terhadap pesan, teks, dan konten. Kekuatan menentukan bentuk akhir pesan bukan lagi semata dimonopoli produsen melainkan juga dikreasi oleh audiens sendiri. Dengan kata lain, audiens juga aktif memproduksi bentuk-bentuk kebudayaan (Radway 1984; Ang 1985, 1991).

Di level produksi, kajian-kajian media yang semula didominasi riset industri kebudayaan dengan perspektif ekonomi-politik secara perlahan mulai berkembang ke ranah dinamika produksi sebagai proses sosial yang kompleks. Himpunan karya para sarjana 
multidisiplin dalam buku Mayer, Bank, dan Caldwell (2009) berjudul Production Studies: Cultural Studies of Media Industries misalnya, menunjukkan bagaimana praktik-praktik produksi media dikaji secara komprehensif dengan menggabungkan metode etnografi, analisis budaya, ekonomi, politik dan budaya material. Praktik produksi dilihat tidak semata sebagai bagian dari pertarungan pasar global sebagaimana kerap mendominasi kajian politik ekonomi. Akan tetapi, praktik produksi dipandang sebagai bagian yang tak terpisahkan dari proses sejarah sosial, pembentukan kebudayaan, dan kehidupan sehari-hari (Ortner 2009, Zafirau 2009).

Bermula dari latarbelakang itu, paper ini berupaya melihat praktik produksi suatu tayangan di televisi dengan cara demikian. Terlebih ilmu antropologi senantiasa melihat praktikpraktik sosial, termasuk praktik bermedia, secara holistik. Sebagaimana ditekankan Mark Peterson (2009), salah satu keunggulan kajian antropologi dalam melihat praktik bermedia adalah caranya dalam menghubungkan berbagai tahap dalam praktik tersebut dengan kehidupan sehari-hari dan meletakkannya dalam struktur sosial lebih besar.

"Anthropology is better
positioned than many other
disciplines to explore media
practices around the world. Ours
is a discipline accustomed to
linking the richness of everyday
social action to broader
structures. More importantly,
ours is a discipline that tends to
look at media as situated within
other sets of human action rather
than approaching social
phenomena with a priori
assumptions about what media
is" (Peterson, 2009: 121).

Hubungan antara proses produksi budaya dan struktur sosial yang lebih besar kerap diletakkan dalam kerangka pelestarian ideologi dominan, seperti tampak dalam kajian-kajian industri budaya yang terinspirasi Theodor Adorno (1991). Seturut dengan hal itu, para antropolog kerap menaruh perhatian terhadap cara strategi-strategi industri media melahirkan representasirepresentasi kultural dominan. Namun, kajian-kajian belakangan cenderung mengkaji tidak saja dari perspektif struktur kelembagaan industri media, melainkan juga dari perspektif agensi dan konteks sosial produsen kebudayaan (Abu-Lughod, et al, 2002: 17).

Karena itulah, dalam paper ini, titik perhatian lebih diberikan pada dinamika praktik para aktor yang terlibat dalam proses produksi. Lebih lanjut, para aktor tersebut tidak muncul dari ruang sosial yang kosong, melainkan berangkat dari ruang sosial yang tidak sama sehingga dapat diasumsikan masingmasing membawa imaji yang berbeda mengenai produk kebudayaan yang ingin mereka bentuk. Sependapat dengan Peterson (2009), tugas antropologi media adalah memperluas dan memperdalam pemahaman mengenai keterlibatan media dalam kehidupan manusia secara keseluruhan. Begitu pula, dalam proses produksi, aktor-aktor yang terlibat diletakkan dalam keseluruhan kehidupan sosialnya, bukan semata dalam peristiwa produksi tayangan.

Salah satu studi produksi yang telah menjadi studi klasik di bidang ini dilakukan oleh sosiolog Todd Gitlin dalam bukunya Inside Prime Time yang pertama terbit pada 1983. Gitlin mengungkap bagaimana programprogram televisi yang sukses di Hollywood diproduksi dengan mewawancarai orang-orang yang terlibat di dalamnya, seperti produser eksekutif, penulis naskah, aktor/pemain yang tampil, agen aktor, dan pengiklan. Sebelum Gitlin, tidak ada seorang pun 
yang menganalis jalur-jalur yang menghubungkan manajemen dengan produser acara, atau upaya-upaya yang dilakukan oleh pengiklan, penulis, dan pelobi untuk memengaruhi tayangan televisi Amerika.

Kontribusi penting dari riset Gitlin (1983) adalah menguraikan pentingnya peran dan kegiatan selain yang dilakukan oleh produser dalam proses produksi tayangan televisi. Sebelum Gitlin, riset produksi cenderung berfokus pada peran produser saja, seperti riset yang dilakukan Muriel Cantor (dalam Gitlin, 1983) di akhir 1960-an. Riset yang diterbitkan dalam buku berjudul The Hollywood TV Producer: His Work and His Audience (dalam Gitlin, 1983) ini menonjol sebagai salah satu dari sedikit kajian sosiologis tentang produksi televisi kontemporer.

Dengan memperluas fokusnya pada orang-orang lain yang juga terlibat dalam proses pembuatan suatu tayangan, termasuk pada pihak manajemen dan pengiklan, Gitlin mengungkapkan negosiasi-negosiasi yang dilakukan produser dalam mewujudkan imaji kreatifnya. Dengan ini, Gitlin juga memberikan kerangka untuk melihat proses produksi tayangan televisi, yang kemudian digunakan oleh penelitipeneliti selanjutnya untuk memahami praktik-praktik yang memengaruhi proses produksi budaya. Gitlin pun mengungkapkan bahwa proses produksi sesungguhnya tidak bisa diprediksi seperti yang diteorikan oleh Miege dan Hesmondhalgh (dalam Bayer, Banks, \& Caldwell, 2009), sebagai operasi industri media yang kompleks, ambivalen, dan penuh kontestasi.

Riset-riset produksi tayangan televisi pasca Gitlin kemudian berkembang tidak hanya pada tempat tayangan itu diproduksi, tapi juga terkait dengan hal-hal lain. Menurut peneliti televisi Horace Newcomb dan Amanda Lotz (dalam Bayer, Banks, Caldwell,
2009), ada lima tingkat analisis yang dipakai dalam studi produksi tayangan televisi hingga saat ini. Pertama, politik ekonomi nasional dan internasional, misalnya studi produksi televisi di Kanada dalam kaitannya dengan imperialisme budaya dari Amerika Serikat yang dilakukan oleh Levine dan Newman (2011). Kedua, konteks industri yang spesifik, misalnya industri televisi kabel di Amerika. Ketiga, stasiun televisi tertentu, misalnya studi terhadap produksi tayangan yang dibuat olehh BBC. Keempat, produksi suatu tayangan televisi, seperti yang dilakukan oleh Gitlin dan Cantor. Kelima, studi tentang produksi dan industri media dengan topik tertentu, misalnya isu feminisme dalam produksi televisi.

\section{Konsep Kebudayaan Termediasi}

Paper ini menggunakan konsep kebudayaan termediasi (mediated culture) menurut Kelly Askew dan Richard R Wilk (2002) dalam The Anthropology of Media A Reader. Dalam konsep ini, kebudayaan lahir dalam kaitannya dengan keberadaan media yang tidak sekadar menempatkannya dalam relasi antara organisasi media dan orang, tetapi menghubungkan orang-orang yang melebihi batas geografis mereka. Hubungan tersebut diletakkan dalam relasi produsen-konsumen, produseraudiens.

Konsep kebudayaan ini sebenarnya bukan hal yang baru. Salah satu anropolog yang mengkaji konsep kebudayaan ini adalah William Mazzarella (2004) dalam artikelnya Culture, Globalization and Mediation. Dalam pembahasannya, ia mengangkat isu "mediasi" sebagai konsep kunci untuk melihat kebudayaan dalam kerangka fenomena globalisasi. Globalisasi menyebabkan perubahan terhadap konsep kebudayaan yang pada awalnya memiliki batasan jelas menjadi sesuatu yang sangat kompleks. Hal ini menyebabkan kebudayaan dan identitas 
sebuah kelompok masyarakat, yang pada awalnya sangat jelas, menjadi susah untuk diidentifikasi.

Merespons perkembangan tersebut, Mazzarella mengajukan konsep mediasi melalui perkembangan teknologi informasi yang mewujud dalam bentuk utama berupa media massa. Media massa kemudian ditempatkan sebagai aspek kunci yang membentuk nilai-nilai yang signifikan dalam sebuah kebudayaan. Mazzarella secara optimis melihat proses yang terjadi dalam kerja media sebagai pembentuk kebudayaan itu sendiri. Media dan proses mediasi menjadi dua konsep kunci dalam memahami kebudayaan karena memungkinkan sebuah kelompok untuk mengamhil pesan sekaligus membentuk kembali pesan tersebut dan menyebarkannya untuk kepentingannya.

Hal tersebut dimungkinkan oleh kemampuan media memainkan fungsi mirroring yang memberikan akses kepada individu dan masyarakat untuk melihat citra diri dan orang lain. Di sinilah sebenarnya media menjadi mediator antara kebudayaan dan masyarakat serta mediasi antara kebudayaan kelompok tersebut dan kebudayaan kelompok masyarakat lain. Fungsi mediasi tersebut dilakukan ketika media massa merepresentasikan sebuah kebudayaan dan kemudian mengembalikan citra (merefleksikan) kebudayaan tersebut kepada kelompok masyarakat yang memiliki kebudayaan tersebut. Media massa juga memungkinkan kelompok masyarakat tersebut membandingkan kebudayaannya dengan kebudayaan kelompok lain yang dapat mereka saksikan melalui media.

Di sini proses mediasi terjadi dalam dua tahap. Pertama, pajanan informasi di media akan membuat kelompok masyarakat mengambil jarak dengan identitasnya. Tapi, pada tahap kedua, kelompok masyarakat tersebut mengakui keberadaan identitas akan identitas mula yang dimiliki dan perbedaannya dengan identitas yang diusung oleh kelompok lainnya, seiring dengan semakin intimnya relasi kelompok masyarakat tersebut dengan media massa. Mazzarella menyebut kedua tahap itu sebagai proses pengambilan jarak (self-distancing) dan pengakuan diri (self-recognition).

Garis besar konsep kebudayaan yang termediasi yang dikemukakan Mazzarella di atas berbeda dengan konsep kebudayaan lainnya, khususnya untuk aspek batas antara satu kebudayaan dan kebudayaan lainnya. Definisi mengenai lokalitas kebudayaan pun menjadi sangat kompleks. Seperti dijelaskan Mazzarella dalam artikel tersebut, dalam suatu tindakan yang dilakukan, terdapat unsur dari kebudayaan lain yang sudah terserap menjadi kebudayaan lokal. Minuman yang diminum merupakan air mineral dalam kemasan, komputer yang digunakan merupakan hasil produksi negara lain, pakaian yang dikenakan juga tidak terlepas dari pengaruh kebudayaan kelompok lain.

Pentingnya keberadaan media massa dalam memediasi kebudayaan juga dipaparkan oleh beberapa antropolog lain. Menjelang akhir abad ke-20, para antropolog sudah melihat makin pentingnya media dalam kehidupan sehari-hari di berbagai tempat, tidak hanya di dunia Barat. Pada tahun 1991, Arjun Appadurai (1996) bahkan merasa perlu mengeluarkan konsep mediascape sebagai perangkat analitis untuk melihat fenomena produksi dan sirkulasi media yang melampaui batasan-batasan geografis. Appadurai hendak menegaskan bahwa antropologi perlu melahirkan konsep baru yang mampu menangkap gejala media yang makin melekat dalam berbagai dimensi kehidupan. Kita tahu bagaimana hari ini kehidupan sehari-hari kita tidak lepas dari pengaruh televisi, film, video, radio dan, belakangan, berbagai bentuk isi di internet. 
Oleh karena itu, Abu-Lughod, Ginsburg, dan Larkin (2002) menyarankan untuk menangkap gejalagejala sosiokultural yang berjalin erat dengan media semacam itu, dibutuhkan suatu konsep kebudayaan yang tidak memperlakukan batas-batas wilayah, perilaku, dan nilai kebudayaan tertentu sebagai sesuatu yang konkret (tangible). Hal ini disebabkan resepsi media bekerja melampaui, misalnya, ruang tamu tempat orang menonton televisi. Selain itu, produksi media juga tidak selesai di dalam studio, melainkan berlanjut menjadi bagian dari rangkaian kegiatan dan wacana keseharian, yang pada gilirannya menentukan bentuk-bentuk tindakan yang kompleks di tataran sosial yang lebih besar (Abu-Lughod, Ginsburg, dan Larkin, 2002:1).

Di tengah perubahan lanskap sosial-budaya yang dipengaruhi media semacam itu, etnografi sebagai perangkat keilmuan dalam antropologi harus mampu bekerja secara produktif. Para ahli antropologi mengusulkan sejumlah cara, selain melalui mediascape yang disarankan Appadurai, untuk mengubah konsep kerja lapangan dalam etnografi yang biasanya terpaku secara eksklusif pada lokalitas spasial tertentu menjadi "lokalitas" yang multispasial (Appadurai 1996). George Marcus (1998) menyarankan strategi "ikuti hal tersebut" (follow the thing), yang secara produktif diterapkan para peneliti etnografi untuk melihat bagaimana serial televisi, film, dan radio beralih dari elit produser ke audiens dengan latar berbagai lingkungan budaya yang tidak tunggal (Abu-Lughod, Ginsburg, dan Larkin, 2002: 2).

Upaya-upaya rekonseptualisasi tersebut sekali lagi menegaskan bagaimana di era serba-media, kebudayaan tidak lagi bisa dikonsepsikan sebagai entitas yang terpagari oleh lokalitas, pola tindakan, atau standar nilai tertentu. Berbagai bentuk tindakan, pandangan, dan nilai sudah saling bersinggungan melalui bentuk-bentuk media yang diproduksi dan disirkulasi dari dan ke lokalitas yang berbeda-beda. Ginsburg, Abu-Lughod, dan Larkin memperlihatkan bagaimana efek dari peredaran orang, gagasan, dan objek dengan perantaraan teknologi media memunculkan formasi kolektivitas yang melintasi batas wilayah dan kategori konvensional dari kebudayaan. Inilah yang dimaksud dengan konsep kebudayaan yang termediasi (mediated culture) sebagai dasar pemikiran mengapa studi tentang produksi sebuah tayangan di media televisi perlu dilakukan dengan pendekatan dan caracara penelusuran yang lintas spasial, yang berbeda dari pendekatan dan caracara penelusuran yang biasa dilakukan dalam kerangka konsep kebudayaan konvensional.

Merujuk kepada konsep kebudayaan Mazzarella (2004) di atas yang menekankan pada konsep mediasi, suatu tayangan yang marak secara kuantitatif di televisi misalnya umumnya merupakan cerminan sebuah fenomena sosial. Konsep mediated culture dari Mazzarella memberi pemahaman bahwa suatu tayangan merupakan cerminan sebuah kebudayaan yang dimiliki oleh sebuah kelompok masyarakat. Disebut sebagai cerminan karena proses produksi tayangan tersebut pada dasarnya bukanlah proses yang berada di ruang hampa. Sebaliknya, proses produksi tayangan tersebut merupakan upaya untuk mengambil cerminan kebudayaan yang muncul dalam masyarakat. Tayangan tersebut kemudian memantul kembali untuk memengaruhi kebudayaan di masyarakat tersebut.

Misalnya untuk contoh kasus tayangan religi, penyebutan maraknya kuantitas tayangan religi di televisi merupakan upaya untuk menggambarkan dominasi moda teknologi komunikasi tersebut memengaruhi tata cara penyampaian dan isi religi yang bersangkutan. Ketika moda komunikasi 
masih didominasi media tatap muka, para pendakwah lebih mengutamakan ketenangan untuk mendengarkan dan merenungkan isi ceramah yang disampaikan. Begitupun terhadap materi dakwah yang memungkinkan sekali isi ceramah tatap muka menjadi lebih mendalam, utuh, dan menyeluruh karena durasi waktu yang lebih lama. Saat itu gaya orang berdakwah menjadi lebih mengutamakan kedalaman isi. Ketika kemudian muncul moda komunikasi berupa media tulis, misal buku, tata cara penyampaian dan isi pesan agama pun berubah. Karakteristik buku mengharuskan isi dakwah agama sarat dengan berbagai dalil keagamaan untuk menguatkan argumen yang disampaikan. Demikian halnya dengan kemunculan media audio yang memengaruhi cara penyampaian dakwah dan isinya menjadi lebih ringan, menghibur, dan mudah dicerna karena memang terbatasi oleh durasi. Kemunculan media televisi tentu saja juga akan memengaruhi gaya dan isi materi religi.

Penjelasan tentang tayangan religi sebagai fenomena sosial tidak hanya berhenti di sini karena akan cenderung menjadi determinisme teknologi. Sebagaimana dinyatakan dengan sangat baik oleh Van Loon (2008) bahwa teknologi "membingkai" dunia, mengatur cara-cara tertentu dalam bertindak, tapi bentuk dan hasil dari pembingkaian dan pengaturan itu tidak dapat diprediksi begitu saja, melainkan senantiasa melibatkan hubungan sosial dan konteks kultural yang melingkupinya.

$$
\text { Merujuk kepada konsep }
$$

mirroring Mazzarella (2004), tayangan religi yang diproduksi stasiun televisi membentuk model dan isinya sendiri yang kemudian dipantulkan kembali ke masyarakat sehingga model dominan juga berpengaruh dalam pembentukan kebudayaan keagamaan di masyarakat, khususnya yang banyak terkena terpaan tayangan religi. Pengaruh tersebut paling tidak dapat dilihat pada kemiripan model dakwah yang menggunakan tayangan religi di televisi sebagai acuan atau role model.

\section{Ranah Produksi Budaya}

Bersandar pada gagasan Bourdieu (1993), proses produksi suatu tayangan dengan para aktor saling berelasi dan berstrategi satu sama lain, mentransformasi sumberdaya, dan mempersaingkan imajinasi dalam upaya memenangkan suatu representasi kultural dapat dipandang secara koheren sebagai sebuah ranah (field). Ranah ini tidak terbatasi oleh ruang konkrit tempat produk budaya itu berlokasi-yang akan berisiko membatasi analisis hanya pada interaksi yang terjadi pada ruang fisik tertentu (studio, misalnya), melainkan juga oleh sejauhmana aktor-aktor berhubungan dalam keseluruhan proses produksi (lihat juga Bourdieu, 2005: 30$31)$.

Konsep ranah memungkinkan dapat melihat tindakan subjek-subjek dalam hubungan sosial yang nyata, tanpa harus terjebak pada determinisme struktur sosial maupun ekonomis yang umumnya mewarnai kajian ekonomipolitik. Di samping itu, konsep ranah juga memberi ruang bagi peneliti untuk mengamati lebih spesifik jaringan hubungan aktor-aktor yang terpola dalam serangkaian praktik tertentu dan relatif otonom dari struktur sosial yang lebih besar (Bourdieu, 1993). Pendek kata, analisis lebih dekat terhadap berbagai usaha, tarik-menarik, pengambilan posisi, dan strategi aktor-aktor dalam menegosiasikan imajinasi yang membentuk produk tayangan televisi.

Di dalam ranah produksi kebudayaan, terdapat dua jenis logika yang bekerja. Pertama, logika yang diturunkan dari logika pasar, yakni yang menghendaki bahwa setiap produk budaya diukur kesuksesannya berdasarkan keuntungan komersial yang 
diperoleh. Kedua, logika yang diturunkan dari persepsi tentang "kualitas" produk budaya. Dalam hal karya seni, kualitas itu kerap diidentikkan dengan istilah "seni untuk seni". Dalam hal itu pendefinisian kualitas ini bukanlah ukuran komersial, melainkan jaringan antara pelaku seni, kurator, kritikus, lembaga-lembaga kesenian dan penganugerahan, perguruan tinggi, dan lain-lain (Bourdieu, 1993; Moore, 2007).

Dalam konteks ini, dua jenis logika itu akan diamati. Diasumsikan, setiap tayangan, di satu sisi, harus mengikuti logika industri yang berorientasi laba, rating, perolehan iklan, dan seterusnya, namun di sisi lain harus mempertimbangkan "kualitas tayangan" yang mempertimbangkan, di antaranya karena sebagai suatu tayangan, legitimasi keagamaan. Bagaimana dinamika dua jenis logika tersebut mewarnai dan membentuk wujud tayangan menjadi penting untuk dilihat secara empiris.

Konsep Bourdieu tentang ranah produksi budaya ditulis dengan merujuk pada konteks produksi seni di Perancis abad ke-19. Ketika konsep tersebut ditarik ke wilayah produksi tayangan religi di televisi abad ke-21 tentu memerlukan sejumlah modifikasi. Melihat perbedaan aspek-aspek antara "karya sastra" dan "tayangan televisi populer" memang penting, namun kerangka konseptual dasar mengenai ranah produksi budaya tetap menjadi pisau analisis yang produktif. Sejumlah sarjana mengadopsi kerangka tersebut untuk menganalisis berbagai bentuk kebudayaan di abad ke-21, misalnya musik punk dan film dokumenter televisi (Moore. 2007).

Bourdieu (1977) mengenalkan konsep ranah bermula dari keinginannya untuk menjelaskan lebih jauh konsep "agen" yang didefinisikan dan mendefinsikan habitus kelompok atau kelas sosial yang merupakan lingkup pergaulan subkultur untuk mengungkap konsep kebudayaannya dalam theory of practice. Konsep agen ini dapat diperoleh konteksnya yang lebih luas dengan mengetahui bagaimana permainan dan hubungan antar habitus dalam proses dominasi. Untuk melihat bagaimana cara-cara dominasi itu terjadi, Bourdieu menggunakan konsep yang disebut ranah (field).

Bourdieu (1977) mengatakan, "I define a field as a network or a configuration, of objective relation between position objectively defined, in their existence and in determination they impose upon their occupant, agent or institution, by their present and potential situation (situs) in the structure of distribution of power (or capital) whose possesion commands acces to specific profit that are at stake in the field, as well as by their objective relation to other position, ..."

Ranah oleh Bourdieu dipandang sebagai struktur sistem sosial yang didiami oleh individu atau kelompok, dan hubungan dari masing-masing posisi akan ditentukan oleh jejaring modal yang disalurkan secara berbeda-beda. Bourdieu (1992: 229-231) membedakan modal dalam empat jenis, yakni modal ekonomi (economic capital) seperti uang, kepemilikan barang dan semacamnya; modal kultural (cultural capital) seperti pengetahuan dan keterampilan dan semacamnya; modal simbolik (symbolic capital) seperti penghargaan sosial dan wibawa; dan modal sosial (social capital) yakni hubungan sosial yang berharga degan orang-orang penting. Di dalam ranah sosial, modal-modal itu bisa mengalir dari satu bentuk modal ke modal yang lain. Kualifikasi pendidikan umpamanya bisa dipertukarkan dengan pekerjaan-pekerjaan yang menguntungkan.

Ranah bagi Bourdieu juga merupakan sistem kekuatan yang hadir di antara berbagai posisi tersebut, ia terstrukturkan secara internal dalam istilah hubungan kekuasaan. Posisi itu menggambarkan hubungan dominasi 
sub-ordinasi atau hubungan setara berdasarkan keunggulan masing-masing kekuatan yang dimiliki oleh modal yang dipertaruhkan dalam arena sosial.

Jenkins (1992: 86) menyebutkan bahwa konsep ranah digunakan dalam tiga cara. Pertama, ia ditaruh dalam arena sosial kekuasaan untuk mengenali kekuasaan yang dianggap dominan atau yang paling unggul dalam masyarakat, dan mengenali sumber dari hubungan kekuasaan yang hirarkhis yang menjadi kerangka bagi arena sosial lainnya. Kedua, mengkonstruksikan peta dari masing-masing posisi yang menyusun arena sosial dan hubungan di antara mereka yang terlibat persaingan di dalamnya. Ketiga, habitus dari masingmasing pelaku dalam ranah dianalisis sejalan dengan strategi-strategi yang merupakan produk dari interaksi antar habitus dan batasan-batasan serta kesempatan yang ditentukan oleh kerangka arena sosialnya.

Kajian tentang ranah memang bukan eksklusif milik Bourdieu. Sebelumnya, antropolog Victor Turner (1974) juga sudah mengembangkan konsep ranah, terutama dalam bukunya Dramas, Fields and Metaphors: Symbolic Action in Human Society. Turner berangkat dari tradisi Manchester, yang dipelopori oleh Max Gluckman, yang berupaya mengatasi problem teoretik yang tidak terjawab dalam kerangka struktural-fungsional yang waktu itu sedang berjaya. Secara ringkas, konsep proses sosial yang dianut Turner mengandaikan bahwa tindakan individu bukanlah merupakan manifestasi naskah yang tercetak dalam struktur. Dinamika sosial, bagi Turner, lebih dari sekadar pertunjukan yang sudah terprogram.

In other words, I do not see social dynamics as a set of "performances" produced by a "program," as certain of my colleagues, notably the New Anthropologists, believe to be the case. Living action, for the human species can never be the logical consequence of any grand design. This is not because of the inveterate tendency of man's "free will" to resist manifest good and manifest reasonableness, as Dostoevsky, Berdyaev, Shestov, and other "alienated" Russians would have it, but because of the processual structure of social action itself (Turner 1974: 13, garis miring oleh penulis).

Jika ditelaah, proposisi Turner bahwa "tindakan hidup, bagi spesies manusia, tidak pernah merupakan konsekuensi logis dari desain besar" tampak sangat dekat dengan konsep agensi dalam teori praktik-nya Bourdieu. Turner kemudian melihat tindakan itu bukanlah berangkat dari individu yang bebas, yang lepas dari sejarah atau tekanan sosial apa pun, melainkan disebabkan oleh "struktur dari tindakan sosial itu sendiri". Tindakan-tindakan aktor itu kemudian saling berinteraksi, berkontestasi dan beradu guna memperebutkan satu sumberdaya yang sama. Di sinilah letak penting konsep "ranah". Bagi Turner, "ranah" mengacu pada "suatu ansambel hubunganhubungan antagonistik antar aktor yang mengarah pada satu hadiah atau nilai yang sama" (Turner 1974: 135). Dengan kalimat lain, "ranah" tidak mengacu pada lokasi fisik konkrit, melainkan merujuk pada kompleksitas hubungan-hubungan yang saling beradu dan bertentangan antar aktor dalam rangka merebut "hadiah" yang sama.

Turner mengajukan konsep lain untuk merujuk lokasi konkrit tempat berlangsungnya hubungan-hubungan tindakan tersebut, yaitu "arena". Menariknya, "arena" bukan saja menjadi latar konkrit tempat para aktor mengejawantahkan berbagai tindakan kontentif (tindakan saling bersaing dan bertarung), melainkan juga menjadi 
ruang para aktor mempersaingkan simbol dan metafor (Turner 1974: 17). Sebagaimana diketahui, Turner merupakan salah satu penggagas penting mengenai simbol dan tindakan simbolik. Di sini, simbol dan metafor merupakan bagian dari tindakan kontentif yang dilancarkan para aktor. Keseluruhan proses kontestasi inilah yang disebut Turner sebagai "drama sosial" (Turner 1974: 17).

John Postill (2013) memberikan telaah yang menarik mengenai kekhasan konsep "ranah" dalam pemikiran Victor Turner ini. Menurut Postill, Turner mempertajam konsep "ranah" lebih jauh menjadi "ranah politik". Ranah politik dalam teori Turner merupakan totalitas hubungan-hubungan antar aktor yang diarahkan kepada imbalan dan nilai yang sama. Ranah politik dibangun bukan berdasarkan pada perilaku, melainkan pada tindakan, khususnya tindakan kolaboratif kelompok yang beorientasi tujuan. Dan meski mengandung konflik dan koalisi, tindakan kolaboratif kerap dibangun untuk melayani tujuan-tujuan tindakan kontentif.

Lebih jauh, tindakan-tindakan pertentangan itu dilancarkan dalam sebuah "arena", yang didefinisikan Turner sebagai "suatu unit spasial yang terpagari, di mana para antagonis, individual maupun kelompok, bertentangan satu sama lain demi merebut satu hadiah atau kehormatan. Arena menjadi "kerangka-kerangka yang eksplisit" di mana "tidak ada yang dibiarkan implisit", dan di mana keputusan-keputusan utama dilakukan di mata publik (Postill, 2013: 4). Gerak sejarah sosial ditentukan oleh berbagai pertentangan yang melibatkan berbagai aktor, lembaga, simbol, dan metafor.

Bagi Turner, episode historis merupakan suatu drama sosial yang di dalamnya terbentang "ranah politik" yang terdiri dari berbagai orang, lembaga, dan sumberdaya yang dimobilisasi untuk mendukung atau menumpas

penyimpanganpenyimpangan. Drama sosial, bagi Turner, merupakan konflik politik yang berasal dari dalam kelompok sosial tetapi dapat menyebar ke kelompok-kelompok lain yang lebih luas kecuali ada tindakantindakan koreksi yang diambil (Postill, 2013: 3-4).

Tampaklah bahwa sesungguhnya konsep "ranah" Turner dan Bourdieu memiliki sejumlah kesejajaran. Postill mengidentifikasi setidaknya tiga poin utama. Pertama, baik Turner maupun Bourdieu menggunakan metafora permainan untuk merujuk "ranah", dan pada saat yang sama menolak konsep aktor rasional sebagai model agensi manusia. Kedua, Bourdieu dan Turner mengkaji arena sosial secara diakronis, sehingga mereka menolak ide-ide struktural-fungsional yang mengasumsikan struktur merupakan entitas yang mengatur diri sendiri. Ketiga, kedua sarjana ini meletakkan konflik sebagai jantung teori mereka. Jika Turner melacak konflik yang bermula dari konflik kelompok yang kemudian melebar merambah ke medan tertentu yang mapan, Bourdieu lebih tertarik pada arah atau trayektori agen individu di dalam arena tertentu (Postill 2013: 5).

Meski demikian, ada konsepkonsep spesifik yang diacu Bourdieu sehingga membedakannya dari Turner. Sebagaimana ditegaskan Postill, Turner berangkat dari konsepsi konflik sosial yang digerakkan kelompok, di mana arena merupakan perwujudan dari perluasan konflik-konflik kelompok sebagai bagian dari drama sosial. Sementara, Bourdieu cenderung melacak dari individu-individu aktor yang terlibat dalam pertentangan-pertentangan. Bourdieu lebih fokus pada strategistrategi para aktor berdasarkan pada "habitus" dan "modal" yang melekat pada dirinya.

Oleh karena itu, pada Bourdieu, konsep ranah tidak dapat dilepaskan dari 
konsep "habitus" dan "modal". Hal penting pada teori Bourdieu adalah posisi aktor dalam hubungannya dengan "modal" yang spesifik melekat pada ranah tertentu (Postill 2013: 4). Bourdieu mengasumsikan bahwa modal-modal itu sendiri yang menentukan pertarungan akan berbeda cirinya dan kemujarabannya dari satu ranah ke ranah lain. Pada ranah tertentu, modal A menjadi penentu pertarungan, namun pada medan lain tidak, melainkan modal B.

"Modal" tidak muncul dengan sendirinya, melainkan melalui proses akumulasi yang bersinggungan dengan "habitus". Postill melihat secara tajam bagaimana pada Bourdieu, "habitus" seseorang bukan semata tumpukan kebiasaan-kebiasaan. Habitus merupakan produk sosialisasi di dalam lingkungan budaya tertentu, produk dari waktu yang lama "membaca" dunia sosial dengan pikiran dan tubuh. Ia merupakan "matriks disposisi" yang terhubungkan dengan posisi seseorang baik dalam suatu ruang sosial keseluruhan maupun dalam ranah tertentu. Habitus mengelola persepsi kita tentang diri kita dan agenagen lain. Bagi Bourdieu, ranah adalah domain kehidupan budaya yang mapan, yang lamban berubah, letak para aktorpraktisi mendapatkan 'feel for the game' selama bertahun-tahun. Misalnya, ranah seni, ranah sosiologi, atau ranah olahraga tinju (Postill, 2013: 5).

\section{Simpulan}

Berdasarkan telaah terhadap teori ranah dari Bourdieu (1993) dan Turner (1974), serta konsep kebudayaan termediasi dari Mazarella (2004), penulis mengajukan agurmen bahwa ruang produksi tayangan dapat dilihat sebagai ranah produksi budaya yang relatif otonom yang memiliki logika dan pola permainannya sendiri dan bukan subordinasi dari lingkungan makro (kekuasaan ekonomi politik) sebagai sesuatu yang pasti menentukan arah tindakan dan hasilnya. Dengan berfokus pada ranah produksi telaah ini menunjukkan bagaimana kekuatan ekonomi dominan tidak senantiasa mendominasi proses produksi tayangan. Praktik-praktik dalam ranah produksi tayangan memiliki logikanya sendiri dan praktik tersebut membentuk jalinan sosial dan material yang mengarah pada tujuan tertentu.

Di masa mendatang kajian terhadap ranah tetap akan menjadi topik yang menarik dan menantang dalam kajian antropologi. Dengan berfokus pada ranah produksi suatu kajian antropologi tentang media mampu mengeksplorasi praktik-praktik konkrit yang dijalani aktor-aktor media. Berdasarkan kerangka berpikir seperti di atas, tampak ada sejumlah agenda strategis yang penting untuk diperhatikan dalam kajian antropologi media.

Pertama, teori ranah produksi masih dapat dikembangkan dengan menelaah variasi gejala dan bentuk media. Umumnya suatu kajian terbatasi pada kajian media televisi dan bentukbentuk tayangan tertentu. Penelaahan terhadap bentuk-bentuk media lainnya seperti radio, cetak, layar lebar atau bentuk produk lain misalnya sinetron, film, berita, sandiwara radio, akan menghasilkan analisis komparasi yang menarik, mencerahkan dan kontributif terhadap perkembangan antropologi media..

Kedua, eksperimen atau pengembangan teori ranah produksi dalam kajian media juga dapat diarahkan untuk melihat proses produksi yang melibatkan banyak arena, misalnya bukan saja membatasi pada satu jenis arena produksi, yakni arena produksi live/taping tayangan "Mamah dan Aa Beraksi". Dalam proses produksi media hari ini, banyak produk media yang melibatkan banyak arena, misalnya arena A untuk memproduksi jenis acara $\mathrm{X}$, kemudian arena B untuk jenis $\mathrm{Y}$-yang keseluruhan merupakan satu rangkaian. 
Paradigma prosesual dalam teori ranah produksi memungkinkan untuk melihat proses-proses di berbagai arena. Analisis terhadap proses di satu arena maupun antar satu arena ke arena lain akan menjadi ruang eksperimen yang produktif bagi antropologi media.

Ketiga, hadirnya media baru (new media) memungkinkan simultannya proses produksi dan konsumsi dalam satu arena. Ini akan menjadi wilayah riset yang menantang bagi antropologi media. Teori ranah memiliki keuntungan untuk melihat keseluruhan praktik dan interaksi antar aktor dalam suatu arena (atau beberapa arena di dalam satu ranah), yang memungkinkan untuk menelaah banyak ragam aktivitas - apakah dikategorikan produksi atau konsumsi. Pada titik itu, tentu saja, teori ranah akan diuji kekuatannya sejauh mana mampu menjadi kerangka analisis dalam melihat proses bermedia dan relasi aktor yang kompleks. Namun, keberanian teoretis dan kejelian etnografis akan mampu membawa peneliti nantinya pada wawasan baru yang mencerahkan.***

\section{Daftar Pustaka}

Abdullah, Irwan. 2006. Konstruksi dan Reproduksi Kebudayaan.

Yogyakarta: Pustaka Pelajar.

Abu-Lughod, Ginsburg, and Larkin B., 2002. Media Worlds: Anthropology on New Terrain. Berkeley: University of California Press.

Adorno, T.W. 1991.The Culture Industry: Selected Essays on Mass Culture, J. Bernstein (ed). London: Routledge.

Alam, Bachtiar. 1998. "Globalisasi dan Perubahan Budaya: Perspektif Teori Kebudayaan”, dalam Jurnal Antropologi Indonesia 21 (54): 111.

Ang, Ien. 1985. Watching Dallas: Soap Opera and the Melodramatic Imagination. London: Methuen. 1991. Desperately Seeking the Audience. London: Routledge.
Appadurai, Arjun. 1996. Modernity at Large: Cultural Dimensions of Globalization. Minneapolis, London: University of Minnesota Press.

Askew, Kelly. 2002. "Introduction to Media Anthropolog”, dalam Kelly Askew \& Ricahrd R Wilk (eds); The Anthropology of Media a Reader (Oxford: Blackwell Publishing). p.1-12.

Bailey, F.G. 1969. Stratagems and Spoils. Oxford: Blackweel.

Baudrillard, J. 1975. The Mirror of Production. Telos Press, St. Louis, MO.

1981. For a Critique of the Political Economy of the Sign. Telos Press, St. Louis, MO.

Bourdieu, Pierre. 1977. The Outline of a Theory of Practice, trans. R. Nice. Cambridge M.A.: Cambridge University Press. 1992. Language and

Symbolic Power. Cambridge: Polity Press.

1993. The Field of Cultural Production: Eassys on Art and Literature. New York: Columbia University Press. 1996. On Television.

New York: The New Press. 1998. Practical on the Theory Reason of Action. California, Stanford: Stanford University Press. . 2005. Distinction: a Social Critique of a Judgement of Taste. trans. R. Nice. Cambridge, M.A.: Cambridge University Press. 2010. Arena Produksi

Kultural: Sebuah Kajian Sosiologi Budaya. Terjemahan Yudi Santosa. Yogyakarta: KreasiWacana.

Brauchler, B., dan Postill, J. (2010). "Theorizing Media and Practice", dalam Anthropology of Media Vol. 4. New York: Berghahn Books.

Cantor, Muriel. 1972. The Hollywood TV Producer: His Work and His 
Audience. New York: Routledge.

Durkheim, E., 1976. The Elemementary Forms of The Religious Life. Terjemahan J.E. Swam: . London: Allen-Unwin.

Fiske, John and Hartley, John. 2003. Reading Television. London: Routledge.

Fiske, John. 1987. Television Culture: Popular Pleasures and Politics. London: Routledge.

Fisher, Michael M.J. 200). "Culture and Cultural Analysis as Experimental Systems", dalam Cultural Anthropology 22 (1): hal 1-65.

Gitlin,Todd. 1983. Inside Prime Time. New York: Pantheon.

Hall, Stuart., et. al. (eds). (1980). Culture Media Language. London: Routledge.

Hariyadi. 2010. Islamic Popular Culture and the New Identity of Indonesian Moslem Youths. Makalah dipresentasikan pada "18th Biennial Conference of the Asian Studies Association of Australia" di Adelaide. Australia: 5-8 July 2010.

Hefner, Robert. W. 2000. Islam Pasar Keadilan Artikulasi Lokal, Kaptialisme dan Demokrasi. Yogyakarta: LkiS

Hefner, Robert. W. dan Patricia Horvatich. 2001. Islam di Era Negara-Bangsa: Politik dan Kebangkitan Agama Muslim Asia Tenggara. Yogyakarta: TW Yogya

Irianto, Maladi, Agus. 2008. Kontestasi Kekuasaan Sajian Acara Televisi: Studi tentang Program Tayangan Infotainment.Disertasi Doktoral Program Studi Antropologi. Depok: Universitas Indonesia.

Jenkins, Richard. 1992. Key Sociologist Pierre Bourdieu. London: Routledge

Kitley, Philip. 2000. Konstruksi Budaya Bangsa di Layar Kaca. Jakarta: PT Media Lintas Inti Nusantara

Kitiarsa, Pattana. 2008. "Religious Commodifications in Asia", dalam
Pattana Kitiarsa (ed): Religious Commodifications in Asia: Marketing Gods (New York: Routledge). p.1-13

Lukens-Bull, $\quad$ Ronald. 2008.

"Commodification of Religion and

The 'Religification' of Commodities: Youth Culture and Religious Identity", dalam Pattana Kitiarsa (ed): Religious Commodifications in Asia: Marketing Gods (New York: Routledge). p.220-234

Mayer, V., Banks. 2009."'Introduction to Production Studies", dalam Bank V Mayer, Miranda J., Caldwell, dan John T (Eds) Production Studies: Cultural Studies of Media Industries (New York: Routledge). p1-5

Mazzarella, William. 2004. "Culture Globalization, Mediation", dalam Annual Review of Anthropology. 33: 345-367.

McQuail, Denis. (1983). Mass Communication Theory: an Introduction. London: Sage Publication.

Moore, Ryan. 2007. “Friends Don't Let Friends Listen to Corporate Rock: Punk as a Field of Cultural Production", dalam Journal of Contemporary Ethnography Volume 36 issue 4. Muzakki, Akh. (2008). "Islam as a Symbolic Commodity: Transmitting and Consuming Islam through Public Sermons in Indonesia", dalam Pattana Kitiarsa (ed); Religious Commodifications in Asia: Marketing Gods (New York: Routledge). p.205-219

Newman, M.Z. dan Levine, E. 2011. Legitimating Television: Media Convergence and Cultural Status. New York: Routledge.

Novenanto, Anton., 2009. Mediated Disaster: The Role of Alternatif and Mainstream Media in the East Java Mud Vulcano Disaster. MA 
Thesis in Department of Cultural Anthropology and Development Sociology. Leiden: University of Leiden.

Ortner, Sherry B. 009. "Studying Sideways: Ethnographic Access in Hollywood," dalam Mayer V. Banks, M. Caldwell (Eds); Production Studies: Cultural Studies of Media Industries (New York: Routledge). p.78-92.

Peterson, Mark, A., 2009. "Response to John Postill Social Anthropology/ Anthropologie Sociale", dalam European Association of Social Anthropologists. Vol 17, (3) p334344.

Pink, Sarah, et al. 2004. Working Images: Visual Research and Representation in Ethnography. London And New York: Routledge

Postill, J. 2013. "Fields as Dynamic Clusters of Practices, Games and Socialitie", dalam Amit (ed); Sociality: An Anthropological Interrogation (Oxford and New York: Berghahn). Diakses melalui $h t t p: / w w w w$.

academia.edu/2046704/

Fields_as_dynamic_

clusters_of_practicgames

and_socialities pada 25 April 2013.

Prato, Giuliana B. 2009. Beyond Multiculturalism: Views from Anthropology. England: Ashgate Publishing.

Radway, Janice. 1984. Reading the Romance. Chapel Hill: University of North Carolina Press.

Rappaport, Roy A. (1999). Ritual and Religion in the Making of Humanity. Cambridge: Cambridge University. Sen, Krisna \& David T. Hill. (2001). Media, Budaya Dan Politik di Indonesia. Jakarta: PT Media Lintas Inti Nusantara

Turner, Victor W. 1969. The Ritual Process: Structure and AntiStructure.New York: Cornell University Press.
Turner, Victor W. 1974. Dramas, Fields and Metaphors: Symbolic Action in Human Society. Ithaca, New York: Cornell University Press.

Turner, Victor W. 1987. The Anthropology of Performance. Preface: Richard Sechechner. New York: PAJ Publications.

Valdivia, Angharad., N. (2003). A Companion to Media Studies. Oxford: Blackwell.

Van Loon, Joost. 2008. Media Technology: Critical Perspectives. Glasgow: Open University Press.

Williams, Raymond. (1974). Television: Technology and Cultural Forms. London: Routledge.

Zafirau, Stephen. 2009. "Audience Knowledge and the Everyday Lives of Cultural Producers in Hollywood", dalam Mayer, Vicki, Banks, Miranda J., Caldwell, John T (eds); Production Studies: Cultural Studies of Media Industries (New York: Routledge).p 302-324. 